\title{
From e-learning to "co-learning": the role of virtual communities
}

\author{
Luigi Colazzo ${ }^{1}$, Andrea Molinari ${ }^{1}$ and Nicola Villa ${ }^{2}$ \\ ${ }^{1}$ University of Trento - Department of Computer and Management \\ Sciences \\ via Inama 5, 38100 Trento, Italy. Tel +390461882144, +390461882344 \\ eMails: colazzo@cs.unitn.it, amolinar@cs.unitn.it \\ ${ }^{2}$ University of Trento - Laboratory of Maieutics \\ via Inama 5, 38100 Trento, Italy. Tel +390461882327 \\ eMail:nvilla@economia.unitn.it
}

\begin{abstract}
The paper presents the analysis of changes introduced in learning environments through a different approach respect to traditional e-learning. In our experience, the introduction of the metaphor of "virtual community" changed not only the relationship between people involved in educational activities (teachers, students, tutors, administrative staff etc.), but also the technical approach to services supplied by the e-learning platform. Thanks to the "community" approach, all the services of a traditional e-learning system (CBT, LMS, LCMS, etc.) must be re-designed, thus allowing to extend the potentialities of services delivered to the audience. The introduction of the "community" concept allow the e-learning platform a greater flexibility: concepts like "role", "rights", "duties"; "hierarchy", "participant", typical of a community system, allow to use e-learning services in different contexts that help a greater integration between educational services and the information system of the institution. We therefore think that e-learning should evolve (at least) towards "co-learning", meaning not only "collaborative-learning", but (more realistically) "community-learning", i.e., using virtual communities to learn.
\end{abstract}

\section{Introduction}

The subject of this work is the conceptual structure of the architecture of elearning systems when these are employed in complex training activities. We will conduct our research on the basis of our experience in developing an e-learning system that is, at the moment, undergoing for the third time a complete revision with the aim of adjusting it to new tasks and scenarios. Drawn from examples taken from the development of these platforms, we will discuss the effects of metaphors used in e-learning systems, their architecture, the evolution of e-learning processes from a 
point of view based on the transfer paradigm (from one teacher to a number of students), shifting to a more realistic paradigm of community-learning [1], that is, upon learning sustained by belonging to a community.

Our research group has been working for years on designing, building, experimenting and managing software platforms in collaborative contexts, at first aimed at learning, and now oriented towards more articulated forms, such as lifelong learning contexts [11] or the integration between the e-learning worlds and the organizational information system. Our first work (On Line Courses - 1998) had been created around the metaphor of "course". Each teaching course carried out by a training institution had been coupled to an "e_course". That is to say, the platform enabled us to define abstract structures called just that "e_courses", and to link them to real structures (the courses carried out by a training institution). An $e_{-}$course enabled its three actors (student, tutor and teacher) to access a certain number of communication services (synchronous and asynchronous), creating a virtual space suitable for forms of blended teaching. The three actors had freedom of action in the different and rigid communication services. This system had been for some years the e-learning platform of some of the Institutes of our University and of some of the training environments outside it. The experience gained from On Line Courses has shown three aspects that have conditioned the evolution of our present platform.

- An e-Learning system used in a real training context cannot act like an isolated system, on the contrary, it has to be considered part and parcel of the information system of a training institution [2].

- The metaphor of the course used in that first attempt was not capable of covering the needs for communication and cooperation that are carried out in the daily work of a training institution [3].

- The daily interaction of subjects within the community of people who take part in a course, needed higher flexibility in defining roles, rights, duties, permissions, etc., within the environment of this "community" of people.

If we consider "communities" $[4,5,6,7,8]$ as aggregations of people and participants, it will be clear that in any training (and not only) situation, the aggregation of people in groups is not limited to the frontal training moment and most of all - does not necessarily have a didactic connotation. A first technological evolution has, therefore, concerned the elimination of this limitation and the introduction of the concept of "community". Both from a conceptual point of view and a technological one, this innovation has lead to a complete rethinking of the elearning platform, certainly a most arduous and difficult task, seeing that the biggest part of "traditional" e-learning services had already been ready and working for years. This effort has, however, brought about a much bigger range of possibilities and a flexibility of the platform, opening the path to some interesting extensions towards what we call "co-learning", that is, a learning environment based upon the concept of community. This concept, as is evident, crosses over the aspects of pure e-learning in order to face environments of social networking, collaboration, and the user participation in the community, all concepts very dear to new environment of web 2.0.

The work is organised as follows: in section two we will introduce the passage from an e-learning approach to that of co-learning. In section three we will describe 
briefly the state of the present version of On Line Communities; in section four we will focus our attention on the crucial question of a virtual community environment, that is to say, roles and permissions to be used in the communication services foreseen by the system.

\section{E-learning and co-learning}

Within the environment of our project of virtual communities the shift from the concept of course to community has shown to be rather natural, as already mentioned in the introduction. The examples of the use of the e-learning platform are various as, for example, the need to be able to invert the teacher - student roles, the possibility to access courses that are not necessarily hinged on academic logics, or the need to aggregate users without passing through the concept of "course". We have avoided to attach external modules to the platform in order to approximate the "community" concept, like some LMS do (i.e., Moodle ${ }^{\mathrm{TM}}$ ). Instead, we have preferred a radical rewrite of the platform, in order to natively implement the complex network of concepts involved in the management of a "virtual community", that is in our view just an ordinary aggregation of people, reunited in a virtual place (hence "virtual community") for the most varied reasons and aims. Some examples of virtual communities of our system are:

- Community of a teacher's thesis writers

- Community of the board members of the faculty

- Community of the secretariat of the presidency

- Community of the trade union representatives of the university

- Community of the course "Database Management System" of the Faculty of Engineering

- Community of the course "Database Management System" of the Faculty of Economics

- Community of the recreational circle of the University of Trento

From these examples it can be seen that a platform that supports the activities of the non educational structures, but with other aims, becomes very useful. We wished to equip from the start our e-learning platform with the possibility of integrating it with the various information systems that concentrate around training situations, for example, the information system of personnel, of research, of marketing, etc. Our conviction, reinforced with the passing of time and the experience we are describing here, is indeed that the e-learning system needs to be considered as an important part of the information system of the institution and that as such it is to be fully integrated with the rest of its components. We find it difficult to envisage an non permeability among e-learning platforms and, for example, with the information system of the students secretariat where the greatest part of data concerning users is kept.

The rethinking of our e-learning platform started with these premises in 2002; this meant re-projecting and re-implementing the old system. In the new platform the metaphor of e-course has been abandoned in favour of the more abstract "virtual community"; "On Line Communities" (the name of the new system) has substituted the old platform in the teaching at our university, at present in use and subject to 
continuous functional innovations. The substitution with a more abstract metaphor has enabled the system to be used for the need of aggregation and collaboration among a wide range of communities like, for instance, an entire training cycle or a student organisation, thus creating a series of services that support the training activities but which are not necessarily correlated.

The differences between services within a platform of virtual community and a classical one based on the metaphor of course, are noteworthy. To give an example, let us imagine a classical e-learning service such as files upload/download; in this way teachers can make available to the users the Learning Objects associated with a teaching course. In an e-learning system based upon the metaphor of "course", the service is cabled in the architecture of the e-course. In an architectural approach based on "virtual communities" the same service must be separated into (at least) three components:

- The service in the strictest sense that makes the upload and download of a file.

- The operational context in which the service is being used.

- The "collaborative" context in which the service must run, that is to say, the management of the permissions concerning the users (upload, download, change of owner, modification, cancellation, transversal action with other communities, etc.)

The same upload/download service could be used to exchange documents to be discussed within the community of the members of the faculty board. It is not possible to use in this context such roles as "student" and "teacher". The same service should, however, be used for organising for instance a photographic competition of the community of students association, for making available didactic material within the virtual community associated to a course, or for reports between thesis writers and their tutors. This circumstance brings with it problems connected to permissions for the use of the services and the roles of the users who, as already mentioned, cannot at present be any longer limited to traditional "student", "tutor" or "teacher".

In a communitarian logic, the role becomes an identifier ascribed from an administrator (of the community) to a specific user or group of users, with associated permissions (according to the type of community). This is how new concepts come about within the technical terminology of the platform: community, type of community, roles, rights, duties, permissions.

Notice, furthermore, how the experience of "community" is, therefore, transversal in the world of training and it embraces any environment where one wants to aggregate people around a concept of "community" mediated through ICT. This is one of the reasons for which our present platform has recently been chosen by the Autonomous Province of Trento (P.A.T.) for the development of a new technological infrastructure for its Lifelong Learning projects ${ }^{1}$. P.A.T. wishes to set up a platform with a double objective: on the one hand setting up training actions

\footnotetext{
${ }^{1}$ Contract between P.A.T. and University of Trento n, 36672/335
} 
aimed at primary and secondary schools and, on the other, the construction of training projects for employees of the public administration that operates on the territory of the Province. The project has a temporary function of three years with the objective of preparing a software to be tested at least on one pilot project.

At present, the project is in its initial phase, meaning, in the process of defining the requirements of the future Lifelong Learning system (LLLs). Our previous (and still valid) experience urged us to open a serious debate on the impact of virtual communities within a training situation that is very different from an academic one. In this context virtual communities are considered as the extension into the virtual of the underlying social dynamics that is widely articulated.

\section{On Line Communities}

On Line Communities is an dynamic web application, based on the metaphor of virtual learning communities in a blended approach $[9,10]$, that guarantees the work organization of cooperative users group named Community.

The topic of Virtual Communities (VC) has been recently explored in the elearning research field. A virtual community is defined as a communication space that is shared by a certain number of people, for whatever reason not only related to educational aspects. Each community has at least one coordinator, and the participants are not anonymous. It comes spontaneous, in fact, to imagine VC as aggregations of subjects created through ICT tools, as an extension in the virtual of a typically "didactic" environment, like the classroom and the course that is held in it. The system has been designed from scratch, and is able to support whatever user of the system (teacher, student, tutor, lecturer, secretary, external expert, porter, dean, chancellor, consultant etc.) in using real, virtual, face-to-face or distance communication. In this way the construction of virtual communities of different nature becomes possible; i.e. in a community of "Faculty Board" all members (teachers, student representatives, representatives of technical staff) are at the same level, that is to say, they have the same role of participants and only the principal of the faculty takes on a special role.

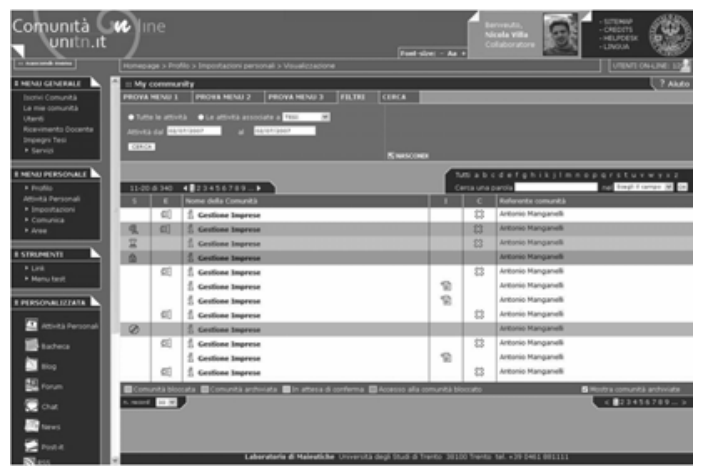

Fig. 1"On Line Communities", the list of communities 
Membership in a community can be obtained automatically, as a right or as a free choice: for example, a student enrolled in the Faculty of Economics and taking the course "Database 2007/2008" is a member of this community by choice and for a limited period of time, while $\mathrm{s} / \mathrm{he}$ is member of the Faculty community automatically. The participants are non-anonymous and they also have (multiple) roles, each role having specific rights and duties within the community. Thus, the actors of the system participate in several virtual communities at the same time, acting in different roles with different rights and duties.

On Line Communities was released on 2005, but was under the experimentation on a limited number of courses from the end of 2003. The Faculty of Economics started to use the system from September 2005, and now other faculties of our University are experimenting it in many types of courses. The system has about 7.500 registered users, a monthly average of 33.000 accesses, and 700.000 total real accesses with a login on the system in two years; the impact on the whole information system of the University and on the daily life organization of members is not trivial.

"On Line Communities" offers different kinds of communication services: whiteboards, forum, chat, calendar, lesson schedule, mail, learning objects download/upload, sticky notes, agenda, syllabus, work areas, etc. All these services are reactive components of the web application and users access them in order to cooperate in organisational and educational processes in various ways.

\section{Permission Management within a Virtual Community}

The set-up we find ourselves facing is very complex; there is an ever increasing need to provide, in the logic of integrating systems, a single moment of aggregation of the various services in order to enable subjects and systems with different interests (if they are not divergent) to access the same object, acting according to their own competences.

In this section we will present five entities, that make it possible to define in detail the logic on which our system is based for the management of the access to the communities. In the first place, the actor who access the system, called by us Person. The person has a Role within the Community, and the hinge between persons community - role is manifold: one and the same person can enrol in different communities, in each of which s/he can take on different roles.

The extension of the "course" concept to the more natural one of "community" has completely changed the concept of "user" of an e-learning system (that is, student, tutor, teacher). Not only, if we include a fundamental element in the study of virtual communities, meaning time, we will understand how temporal management constitutes an important factor in the basic relationship "person - community - role". A typical example is the evolution of the role of a user from "student" to "thesis writer", to "PhD student" and then perhaps "assistant" or "researcher", while always remaining the same person. Such evolution can be a hard test for the traditional elearning systems as well as the information system of the students secretariat, requiring the creation of more types of users for the same person, or cancellation of the previous history for the new needs. 
As already mentioned, time is a factor that radically changes the vision of a colearning system: the virtual community must guarantee the membership of the subjects and the use of their "community rights/duties" according to the role of that moment, with relative complexity. There is, however, another factor, perhaps even more determining in the passage from e-learning to co-learning and that is "inheritability" factor. This factor enormously increases the conceptual, technical and operative complexity of a co-learning system, manifesting itself in at least two central concepts: the roles and the communities. As far as the roles are concerned, it seems evident how the extension of the original system from the metaphor of courses to that of virtual communities, while still remaining in the university teaching environment, has introduced into the system a certain number of new actors with different roles hierarchically related to each other. The hierarchy of roles in a university environment is probably less relevant than in a private or public organisation, but it exists and is important. The further extension to liefelong learning projects makes the group of actors dynamic, that is to say, the system must guarantee the possibility to introduce new actors and, if necessary, change the hierarchy of roles.

This is made necessary by the fact that in liefelong learning experiences the user's contexts of learning can be very different from each other. Some may be based on traditional structures (training courses for the use or a new fiscal regulation), others on very different organisational structures, such as a practising community of professionals who work for the public body in various territorial sectors (like for instance municipal secretaries). Each user has the faculty, after an application process, to accede to a group of Communities, every one of which will comprise a series of Services aimed at teaching or not. At the moment of registering into a community, each user will be identified with a specific Role. Subsequently, all these subjects will need to access the same object through different modalities, called Permissions. It becomes clear that to create this manifold way of accessing/roles/permissions would be senseless in a system based on the metaphor of "course", in as much as it is over-dimensioned. Perhaps this is also the reason why many e-learning platforms do not enter into such details. LMS systems, like the excellent Moodle ${ }^{\mathrm{TM}}$, while introducing the idea of community do not, however, by nature express the concepts connected with the co-learning metaphor, especially not the effect of propagation which the same presents in case of nesting of the community.

The second concept linked to the problem of inheritability is that of "community"; examples of communities that inherit characteristics from "father" communities are most common in the academic world. Take for instance the "Faculty" community which contains a series of "Degree Course" communities, each of which in turn contains various "courses" within which there can be subarticulations (for example per alphabetic order of participants when there are many of them in a course). It is clear and, at the same time, natural and hence indispensable, that there should be within the hierarchy mechanisms of propagation of the basic concepts such as "role", "permission", "rights", "duties". 
The example of a Service could be the register of the lectures where the teacher signs the date, hour and the topic taught in a course; a typical administrative service, useful for counting the hours of a teacher. But if, further to the administrative function, the service also offers the possibility to register the didactic material of each lesson, we will have an interesting mix between support service and didactic service. If we further connect the registry dates with the personal agenda of the teacher, visible (with permissions) to students, we have another integration level, i.e., with the specific "information system" of the community user. At this point, however, inserting such a service into a context of virtual communities, as implemented in our platform, we will need to limit the authority to access such information to a small group of members, for example to teachers. Widening the range, it is possible to imagine guaranteeing the access to the services only to Persons who are duly authorised and identified through a specific Role. Increasing the complexity of management of virtual Communities, each subject or group of subjects will be associated with a Profile, that is, a set of Permissions that consents to take on a specific Role within the community.

The Service "register of the lectures" will be viewable by the members of the community according to different angles, be it that of a simple participant, a teacher or a tutor. Indeed, to each Role are assigned Permissions, for example the role of "teacher" will have assigned permissions for writing, such as changing a line of the lecture register, or associating some type of didactic material to the lectures. In contrast, the student will necessarily have permissions for reading like, for instance, consulting the lecture register. These implications show how a co-learning application like ours will have a degree of intrinsic difficulty much higher than an applicative system that does not need to manage the mechanisms of interaction among members of different communities.

We can sum up the whole debate in the diagram under figure 2 , where all previously mentioned entities are represented. At present, in our system there are about fifty different Roles that identify each user within each Community through the Permissions to be used in the various functions offered by each Service.

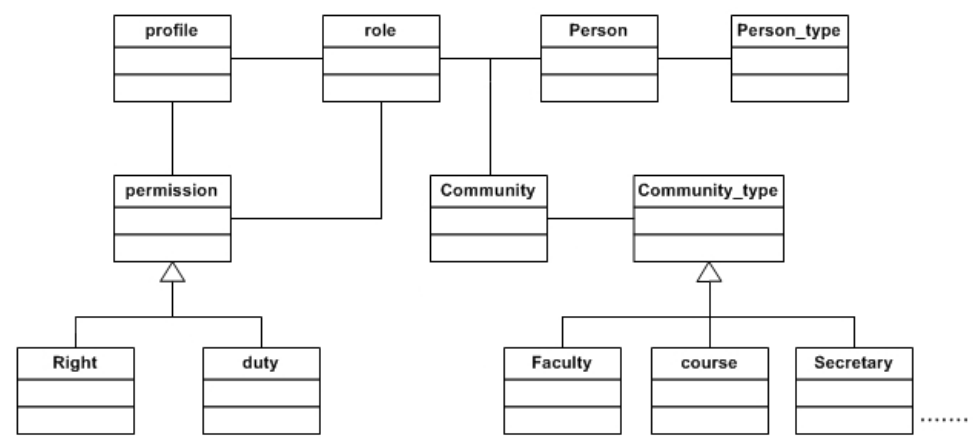

Fig. 2 Relationship between the Entities of On Line Communities

In our system there are, further to a high number of roles, also a series of different Permissions that can also be associated in multiple ways to each role and, 
therefore, the Person who accesses the system. One example is the permission for reading the information offered by a service, or that of reading or modifying the information or, again, the possibility for a user to assign in turn permissions to other participants. The latter, obviously is a very critical type of permission, obtainable only by the administrator of the system and the community; a fundamental step within this process is the management of the registered members who participate in our e-learning tools.

The mechanism that we though of using is based on permitting the administrator to validate or not the registration of a user or to block the accesses for the most varied motives, depending even on the faulty use of the system.

\section{Conclusions}

The paper presents the idea of how the introduction of the concept of virtual community leads to a considerable conceptual change, technical and operative, of an e-learning system, transforming the approach in something that we prefer to call "colearning". We have specifically highlighted the aspect of community of our approach and how it influences the development and use of a new system no longer oriented towards traditional e-learning but, rather, connected to the concepts of "role", "permit", "rights", duties", "inheritability", "time". Perfectly natural aspects in real life but which have to be formalised somehow in a system oriented at virtual communities and no longer at simple courses.

\section{References}

1. Brown A. L., Campione J. C. (1994) Guided discovery in a community of learners, in K. McGilly (a cura di),Classroom lessons: Integrating cognitive theory and classroom practice, Cambridge, MA, MIT Press, 1994, pp. 229-270

2. Colazzo L., Molinari A. (2002), "From Learning Management Systems To Learning Information Systems: One Possible Evolution Of E-Learning”, in Proc. Communications, Internet and Information Technology (CIIT) Conference, St. Thomas, USA - November 18-20, 2002

3. Colazzo L., Haller H., Molinari A. (2007) WAYS - What Are You Studying? A community tool for learners on the move, Proc. of ED-MEDIA 2007, edit by Craig Montgomerie \& Jane Seale,June 25- June 29, 2007; Vancouver BC, Canada

4. Jones S. G., Cybersociety, Sage, London, 1995.

5. Jones S. G., Virtual Culture, Sage, London, 1997.

6. Lévy P., Qu'est-ce que le virtuel?, La Découverte, Paris, 1995 (trad. It. Il virtuale, Raffaello Cortina, Milano, 1997).

7. Rheingold H., The Virtual Community, 1993 (trad. It. Comunità virtuali, Sperling \& Kupfer, Milano, 1994). 
8. Turkle S., Life on Screen. Identity in the Age of Internet, New York, Simon \& Shuster (trad. It. La vita sullo schermo. Nuove identità e relazioni sociali nell'epoca di Internet, Apogeo, Milano, 1997).

9. Brunn H. G., Frank C., (2002) Online Communication: A Success Factor for Blended Learning, in World Conference on E-Learning in Corp., Govt., Health., \& Higher Ed., Vol. 2002, Issue. 1, 2002, pp. 1477-1480

10. Franks P., (2002) Blended Learning: What is it? How does it impact student retention and performance? in World Conference on E-Learning in Corp., Govt., Health., \& Higher Ed., Vol. 2002,Issue. 1, 2002.

11. Fieldhouse R. (2000) Lifelong Learning - Apprendimento lungo tutto l'arco della vita, (Glossario dell'educazione degli adulti in Europa pp 25-26) 